\title{
Telemetry Design Accuracy of Patient's Temperature With IoT Approach
}

\author{
Ahyar Supani ${ }^{1, *}$ Ahmad Bahri Joni ${ }^{1}$ Herlambang Saputra ${ }^{1}$ Indarto $^{1}$ Yuli Andriani ${ }^{2}$
}

${ }^{1}$ State Polytechnic of Sriwijaya

${ }^{2}$ Sriwijaya University

*Corresponding author. Email: ahyarsupani@polsri.ac.id

\begin{abstract}
Health is a good condition of body, soul, and society for someone who lives healthy. The examination of vital signs on the patient's body is to determine a person's health. Temperature is a biological parameter and a major factor in vital signs that must be checked. Taking the patient's temperature poses the risk of transmitting infectious diseases through direct contact. It is now possible to develop a way to measure patient temperature remotely by applying the Internet of Things (IoT) technology to avoid direct contact. This research has focused on the design of remote patient temperature measurement by integrating IoT technology. The IoT technology that has been applied is a wi-fi network that is connected to a medical or paramedical smartphone. An application of a smartphone that is built is a telegram application. The results for the accuracy of the error and the percent error rate of the designed device versus a digital gun thermometer are 0.09 and $0.248 \%$, respectively. It has been proven that temperature telemetry devices have worked well.
\end{abstract}

Keywords: patient temperature, IoT network, telemetry, accuracy, wi-fi

\section{INTRODUCTION}

One of the things that are very important for humans is health because of the good health of the body, soul, and society for someone who lives a healthy life. To determine a person's health can be done by examining the Vital Signs (TTV). One of the human biological parameters that allow the examination of vital signs is body temperature. Checking the patient's body temperature can be done in two ways, namely direct contact and indirect contact to the patient. The direct contact check can use a remote temperature measurement technology called temperature telemetry. Measuring the patient's body temperature through direct contact with the patient, this method poses the risk of disease transmission from the patient and is very susceptible to infection. Checking the patient's body temperature can be done in two ways, namely direct contact and indirect contact with the patient. Direct contact checks can use a remote temperature measurement technology called temperature telemetry. Measuring the patient's body temperature through direct contact with the patient, this method poses the risk of disease transmission from the patient and is very susceptible to infection. It is possible to develop a longdistance measurement of biological parameters. This system has been widely practiced in the health [1], [2], [3] [4], [5], environment [6], and sports sectors [7]. IoT technology can be applied to remote patient temperature measurement systems because IoT networks can be accessed by portable smartphone devices. And the patient's heart details can be collected using an IoT based medical device [8]. In a study [9], comparing the benefits of flood early warning using SMS on smartphones and IoT networks for smartphone access, the results of the study show that people access flood early warning data using the IoT network answered: $5 \%$ totally agree, $60 \%$ agree, and $35 \%$ quite agree. So, we conclude that IoT is very important, easily accessible, and utilized by people in various fields. And also in IoT application areas to be the environmental implications linked with the increased application of IoT products [10].

Furthermore, IoT is a solution to a water quality management system that is seen from several water quality parameter factors such as $\mathrm{pH}$, temperature, and turbidity. the architecture designed with the input of ph, temperature, and turbidity sensors, in which these parameters can be accessed by the public via the internet network [11].

This research has focused on measuring patient 
temperature remotely by integrating Internet of Things (IoT) technology. The IoT network built is a wi-fi network with a medical or paramedic smartphone connection. The smartphone application used is a telegram.

\section{METHODS}

To design a remote patient temperature measurement system by integrating IoT technology which includes an input (temperature sensor), Wi-Fi networks for IoT, and smartphones as shown in Fig. 1.

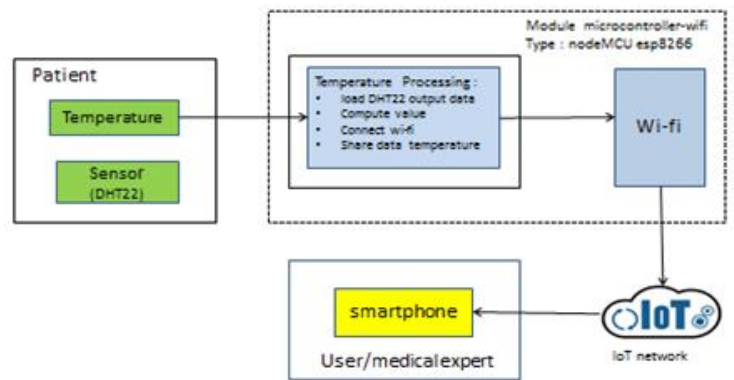

Figure. 1. A block diagram of patient temperature telemetry design

\subsection{Preliminary}

The initial preparation of patient temperature telemetry is a block diagram design as shown in Figure 1. The first block begins with measuring the patient's temperature using a temperature sensor with the DHT22 type, the temperature sensor transfers the patient's body temperature into the form of a digital electrical signal.

Some reasons for using the DHT22 sensor to have a wide temperature and humidity measurement range with the ability to transmit the output signal via a 20 -meter long cable, if the cable is longer than 2 meters, a buffer capacitor of $0.33 \mu \mathrm{F}$ must be connected between pin \# 1 (VCC) and pin \# 4 (GND). DHT22 Technical Specifications, namely power supply: $3.3-6$ Volt DC (typically 5 VDC), digital output signal via a single bus with a speed of 5 ms/operation, detection element: polymer capacitor, sensor type: capacitive (capacitive sensing) ), humidity detection range: $0-100 \% \mathrm{RH}$ (accuracy $\pm 2 \% \mathrm{RH}$ ).

Next, the second block in Figure 1 is a microcontroller-type NodeMCU esp8266. A microcontroller in which there is a wifi module that functions an internet connection and is also able to run the applications in it yourself. In this design, the ESP8266 nodeMCU module functions to read input data in the form of temperature, calculate temperature values, internet connection, share the results of calculated temperature values to smartphone users or medical experts.

And then, the IoT network and smartphone are shown in Figure 1 to connect to the internet via a wifi network that bridges to the user's smartphone, it is any smartphone. Smartphone displays patient temperature data via the telegram application. Telegram application details are not explained in this paper.

\subsection{Preparation of source code}

The listing of the following program is to read the DHT22 temperature sensor data by the microcontroller.

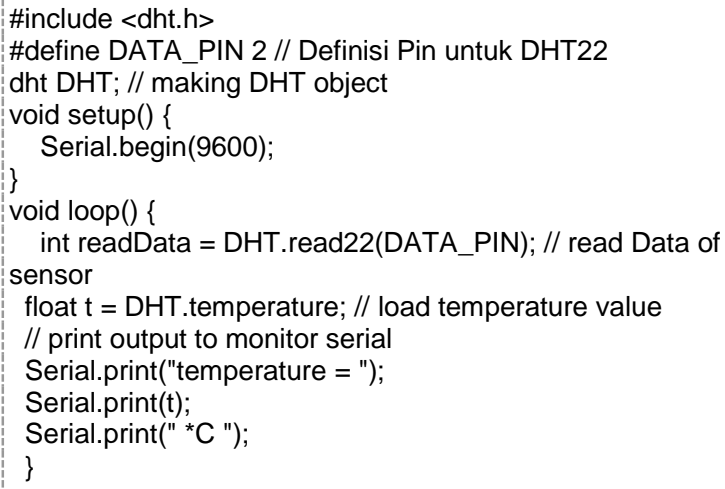

\subsection{Remote temperature measurement testing}

Remote temperature measurement testing has been carried out employing a device temperature sensor that has been made attached to the human body and a digital thermometer gun as a temperature comparison is also fired at the body of the same patient. Meanwhile, smartphones with the telegram application [6] to read or display the patient's temperature are also activated. As for the volunteers who became patients to be tested for his body temperature, he was Ahyar Supani, in good health. The test was carried out for 3 days from 13-102020 to $15-10-2020$, in one day 10 measurement experiments were carried out, and each first measurement was then given a pause of \pm 1 minute aimed at resetting the data on the device and also reduces the risk of reading errors by temperature reading operators. The results of the measured temperature observations are entered in table 1 to table 3. A comparative digital thermometer gun is used to obtain the difference in measurement error to determine the performance of long-distance measurements by applying IoT. The digital thermometer gun specifications are shown in table 1. 
Table 1. Specification of digital thermometer gun

\begin{tabular}{|l|l|}
\hline \multicolumn{1}{|c|}{ Specification name } & \multicolumn{1}{c|}{ Description } \\
\hline Product Nama & $\begin{array}{l}\text { Infrared body } \\
\text { thermometer }\end{array}$ \\
\hline Model name & HG01 \\
\hline Display & $\begin{array}{l}\text { LCD liquid crystal } \\
\text { display }\end{array}$ \\
\hline Power & DC3V \\
\hline Measuring distance & $3-5 \mathrm{CM}$ \\
\hline $\begin{array}{l}\text { Operating environment } \\
\text { temperature range }\end{array}$ & $\begin{array}{l}10 \sim 40{ }^{\circ} \mathrm{C} \text {, humidity } \\
\leq 93 \%\end{array}$ \\
\hline Temperature measuring range & $32{ }^{\circ} \mathrm{C}-42.9^{\circ} \mathrm{C}$ \\
\hline Reaction time & Within 1 second \\
\hline Measuring Accuracy & $\pm 0.2^{\circ} \mathrm{C}$ \\
\hline Auto power off & 30 seconds \\
\hline Battery Alert & $\begin{array}{l}\text { When Battery } \\
\text { capacity is Low }\end{array}$ \\
\hline Backlight & $\begin{array}{l}\text { High Brightness } \\
\text { Backlight }\end{array}$ \\
\hline Product weight & $75 \mathrm{~g}$ \\
\hline Net weight & $7.0 \mathrm{KG}$ \\
\hline Gross weight & $7.5 \mathrm{KG}$ \\
\hline
\end{tabular}

\subsection{Error and Error rate}

Error is the deviation of actual temperature to the measured temperature and error rate is the amount of deviation of the remote temperature measurement design with IoT accessed on a smartphone toward a thermometer gun as a reference temperature. The error rate is expressed in percent $(\%)$ [12], the formula for determining the error rate for measurement data is equation 1 and 2 below.

error ${ }_{2}$ rate $=\left|X-X_{\mathrm{i}}\right|$

\%error_rate $=\left|\frac{X-X_{i}}{x}\right| \cdot 100(\%)$

Error_rate and \%error_rate is the magnitude of the deviation of measurement error of remote temperature measurement using IoT (Xi) toward the temperature measurement data of the digital thermometer gun (X), X is the actual data, $\mathrm{Xi}$ is the measured data.

\section{RESULTS}

Table 2, Table 3, and Table 4 are the results of the experiment of temperature telemetry with IoT technology as stated measured data $\left(\mathrm{X}_{\mathrm{i}}\right)$ and digital thermometer gun as stated actual data (X). The experiments were conducted for three days of respectively.

Table 2 has an actual temperature of $36.2{ }^{\circ} \mathrm{C}$ in the first experiment, and a measured temperature is $36.2{ }^{\circ} \mathrm{C}$. The second experiment has an actual temperature of
$36.3{ }^{\circ} \mathrm{C}$, and a measured temperature is $36.2{ }^{\circ} \mathrm{C}$. the third experiment has an actual temperature of $36.4{ }^{\circ} \mathrm{C}$, and a measured temperature is $36.3{ }^{\circ} \mathrm{C}$. The fourth experiment has an actual temperature of $36.4{ }^{\circ} \mathrm{C}$, and a measured temperature is $36.3{ }^{\circ} \mathrm{C}$. The fifth experiment till the tenth experiment has a similar result with the fourth experiment namely an actual temperature of 36.4 ${ }^{\circ} \mathrm{C}$ and a measured temperature of $36.3{ }^{\circ} \mathrm{C}$. And an absolute value of average error is 0.09 and the \%error rate is $0.248 \%$.

Table 2. An experiment of temperature measuring on the first day

\begin{tabular}{|c|c|c|c|c|}
\hline \multirow{2}{*}{$\begin{array}{l}\text { \#experiment } \\
\text { s }\end{array}$} & \multicolumn{2}{|c|}{ Temperature } & \multirow{2}{*}{ error } & \multirow{2}{*}{$\begin{array}{l}\text { \%error_r } \\
\text { ate } \\
(\%)\end{array}$} \\
\hline & $\mathrm{X}_{\mathrm{i}}\left({ }^{\circ} \mathrm{C}\right)$ & $\mathrm{X}\left({ }^{\circ} \mathrm{C}\right)$ & & \\
\hline 1. & 36.2 & 36.2 & 0.0 & 0.0000 \\
\hline 2. & 36.3 & 36.2 & -0.1 & 0.2762 \\
\hline 3. & 36.4 & 36.3 & -0.1 & 0.2755 \\
\hline 4. & 36.4 & 36.3 & -0.1 & 0.2755 \\
\hline 5. & 36.4 & 36.3 & -0.1 & 0.2755 \\
\hline 6. & 36.4 & 36.3 & -0.1 & 0.2755 \\
\hline 7. & 36.4 & 36.3 & -0.1 & 0.2755 \\
\hline 8. & 36.4 & 36.3 & -0.1 & 0.2755 \\
\hline 9. & 36.4 & 36.3 & -0.1 & 0.2755 \\
\hline 10. & 36.4 & 36.3 & -0.1 & 0.2755 \\
\hline \multicolumn{3}{|c|}{ Average } & $-0,09$ & 0,2480 \\
\hline
\end{tabular}

The second-day experiment in table 3, the first experiment, has an actual temperature of $36.2{ }^{\circ} \mathrm{C}$, and a measured temperature is $36.2{ }^{\circ} \mathrm{C}$. The second experiment has an actual temperature of $36.3{ }^{\circ} \mathrm{C}$, and a measured temperature is $36.2{ }^{\circ} \mathrm{C}$. The third experiment has an actual temperature of $36.4{ }^{\circ} \mathrm{C}$, and a measured temperature is $36.3{ }^{\circ} \mathrm{C}$. The fourth until the tenth experiment has a similar result with the third experiment. An absolute value of average error is 0.09 and the \%error rate is $0.248 \%$.

Table 3. An experiment of temperature measuring on the second day

\begin{tabular}{|c|c|c|c|c|}
\hline \multirow{2}{*}{\begin{tabular}{|} 
\#experiment \\
s
\end{tabular}} & \multicolumn{2}{|c|}{ Temperature } & \multirow{2}{*}{ error } & $\begin{array}{c}\text { \%error_rate } \\
(\%)\end{array}$ \\
\cline { 2 - 3 } & $X_{i}\left({ }^{\circ} \mathrm{C}\right)$ & $X\left({ }^{\circ} \mathrm{C}\right)$ & & \\
\hline 1. & 36.2 & 36.2 & 0.0 & 0.0000 \\
\hline 2. & 36.3 & 36.2 & -0.1 & 0.2762 \\
\hline 3. & 36.4 & 36.3 & -0.1 & 0.2755 \\
\hline 4. & 36.4 & 36.3 & -0.1 & 0.2755 \\
\hline 5. & 36.4 & 36.3 & -0.1 & 0.2755 \\
\hline 6. & 36.4 & 36.3 & -0.1 & 0.2755 \\
\hline 7. & 36.4 & 36.3 & -0.1 & 0.2755 \\
\hline
\end{tabular}




\begin{tabular}{|c|c|c|c|c|}
\hline 8. & 36.4 & 36.3 & -0.1 & 0.2755 \\
\hline 9. & 36.4 & 36.3 & -0.1 & 0.2755 \\
\hline 10. & 36.4 & 36.3 & -0.1 & 0.2755 \\
\hline \multicolumn{3}{|c|}{ Average } & $-0,09$ & 0,2480 \\
\hline
\end{tabular}

In the third day experiment in table 4 , the first experiment has an actual temperature of $36.2{ }^{\circ} \mathrm{C}$, and a measured temperature is $36.2{ }^{\circ} \mathrm{C}$. The second experiment has an actual temperature of $36.3{ }^{\circ} \mathrm{C}$, and a measured temperature is $36.2{ }^{\circ} \mathrm{C}$. The third temperature has an actual temperature of $36.4{ }^{\circ} \mathrm{C}$, and a measured temperature is $36.3{ }^{\circ} \mathrm{C}$. The fourth until the tenth experiment has a similar result with the third experiment.

Table 4. An experiment of temperature measuring on the third day

\begin{tabular}{|c|c|c|c|c|}
\hline \multirow{2}{*}{$\begin{array}{l}\text { \#experime } \\
\text { nts }\end{array}$} & \multicolumn{2}{|c|}{ Temperature } & \multirow{2}{*}{ error } & \multirow{2}{*}{$\begin{array}{l}\text { \%error } \\
\text { rate } \\
(\%)\end{array}$} \\
\hline & $\mathrm{X}_{\mathrm{i}}\left({ }^{\circ} \mathrm{C}\right)$ & $\mathrm{X}\left({ }^{\circ} \mathrm{C}\right)$ & & \\
\hline 1. & 36.2 & 36.2 & 0.0 & 0.0000 \\
\hline 2. & 36.3 & 36.2 & -0.1 & 0.2762 \\
\hline 3. & 36.4 & 36.3 & -0.1 & 0.2755 \\
\hline 4. & 36.4 & 36.3 & -0.1 & 0.2755 \\
\hline 5. & 36.4 & 36.3 & -0.1 & 0.2755 \\
\hline 6. & 36.4 & 36.3 & -0.1 & 0.2755 \\
\hline 7. & 36.4 & 36.3 & -0.1 & 0.2755 \\
\hline 8. & 36.4 & 36.3 & -0.1 & 0.2755 \\
\hline 9. & 36.4 & 36.3 & -0.1 & 0.2755 \\
\hline 10. & 36.4 & 36.3 & -0.1 & 0.2755 \\
\hline \multicolumn{3}{|c|}{ Average } & $-0,09$ & 0,2480 \\
\hline
\end{tabular}

Every table of experimental results was carried out ten times to determine the level of accuracy of the device "design of patient temperature telemetry with applying IoT technology". Table 2, Table 3, and Table 4 performs average \%error rate are $0.2480 \%, 0.2756 \%$, and $0,2480 \%$, respectively. And the average error is $0.09,0,1$, and 0.09 , respectively. The $\%$ error rate of measurement is less than $0.3 \%$, or close to $0 \%$ if rounded because it is less than $0.5 \%$. And the average measured error is 0.09 and 0.1 .

We also experimented with result comparison with other a designed temperature device as telemetry with IoT which is a comparison device built by Romi. Table 5, Table 6, and Table 7 are the experiment results built by Romi. Every table has 6 times measurements with a similar reference temperature. The reference temperature in a variable $(\mathrm{X})$ include $30^{\circ} \mathrm{C}$ in table 5 , reference temperature $33{ }^{\circ} \mathrm{C}$ in table 6 , and reference temperature $35{ }^{\circ} \mathrm{C}$ in table 7 , respectively. The measured temperature is a variable $\mathrm{Xi}$. A measured temperature $(\mathrm{Xi})$ is the temperature that is read by a designed device.
Table 5, in \#experiment 1,2 , and 3 has a measured temperature of $29^{\circ} \mathrm{C}$ and \#experiment 4,5 , and 6 has a measured temperature decrease one number namely 28 ${ }^{\circ} \mathrm{C}$. Of six experiments, the average error is 1.5 , and the \%error rate is $5.00 \%$.

Table 5. Experiment of temperature measuring on reference temperature $30^{\circ} \mathrm{C}$

\begin{tabular}{|c|c|c|c|c|}
\hline \multirow{2}{*}{ \#experiments } & \multicolumn{2}{|c|}{\begin{tabular}{c}
\multirow{2}{*}{$\left({ }^{\circ} \mathrm{C}\right)$} \\
emperature
\end{tabular}} & $\begin{array}{c}\text { \%error } \\
\text { rate } \\
(\%)\end{array}$ \\
\cline { 2 - 5 } & $X$ & $X i$ & & \\
\hline 1 & 30 & 29 & 1 & 3,33 \\
\hline 2 & 30 & 29 & 1 & 3,33 \\
\hline 3 & 30 & 29 & 1 & 3,33 \\
\hline 4 & 30 & 28 & 2 & 6,67 \\
\hline 5 & 30 & 28 & 2 & 6,67 \\
\hline 6 & 30 & 28 & 2 & 6,67 \\
\hline & \multicolumn{2}{c}{ Average } & 1.5 & 5.00 \\
\hline
\end{tabular}

And then, table 6 has a reference temperature of 33 ${ }^{\circ} \mathrm{C}$, the first experiment has $31{ }^{\circ} \mathrm{C}$ as a measured temperature, the second experiment, the measured temperature is also $31{ }^{\circ} \mathrm{C}$, and in the third experiment, it increases one number namely $32{ }^{\circ} \mathrm{C}$. The fourth, fifth, and sixth experiments have a constant temperature namely $31{ }^{\circ} \mathrm{C}$. The average error of six measurements is 1.83 , and the \%error rate is $5.56 \%$.

Table 6. Experiment of temperature measuring on reference temperature $33^{\circ} \mathrm{C}$

\begin{tabular}{|c|c|c|c|c|}
\hline \multirow{2}{*}{ \#experiments } & \multicolumn{2}{|c|}{$\begin{array}{l}\text { temperature } \\
\left({ }^{\circ} \mathrm{C}\right)\end{array}$} & \multirow{2}{*}{ error } & \multirow{2}{*}{$\begin{array}{l}\text { \%error } \\
\text { rate } \\
(\%)\end{array}$} \\
\hline & $x$ & $X i$ & & \\
\hline 1 & 33 & 31 & 2 & 6.06 \\
\hline 2 & 33 & 31 & 2 & 6.06 \\
\hline 3 & 33 & 32 & 1 & 3.03 \\
\hline 4 & 33 & 31 & 2 & 6.06 \\
\hline 5 & 33 & 31 & 2 & 6.06 \\
\hline 6 & 33 & 31 & 2 & 6.06 \\
\hline \multicolumn{3}{|c|}{ Average } & 1.83 & 5.56 \\
\hline
\end{tabular}

The last, table 7 is an experiment of temperature measurement on a reference temperature of $35^{\circ} \mathrm{C}$. The first experiment has a measured temperature of $33{ }^{\circ} \mathrm{C}$. The second experiment has a measured temperature of $33{ }^{\circ} \mathrm{C}$, the third experiment has a measured temperature of $33{ }^{\circ} \mathrm{C}$, the fourth experiment has a measured 
temperature of $33{ }^{\circ} \mathrm{C}$, the fifth experiment has a measured temperature of $33{ }^{\circ} \mathrm{C}$, and the sixth experiment has a measured temperature $33{ }^{\circ} \mathrm{C}$. So, the average error of six experiments is 2 , and the \%error rate is $5.71 \%$. In the experiment in Table 7 , the designed device has a constant measured temperature.

Table 7. Experiment of temperature measuring on reference temperature $33^{\circ} \mathrm{C}$

\begin{tabular}{|c|c|c|c|c|}
\hline \multirow{2}{*}{ \#experiments } & \multicolumn{2}{|c|}{$\begin{array}{c}\text { temperature } \\
\left({ }^{\circ} \mathrm{C}\right)\end{array}$} & \multirow{2}{*}{ error } & \multirow{2}{*}{$\begin{array}{c}\text { \%error rate } \\
(\%)\end{array}$} \\
\hline & X & Xi & & \\
\hline 1 & 35 & 33 & 2 & 5,71 \\
\hline 2 & 35 & 33 & 2 & 5,71 \\
\hline 3 & 35 & 33 & 2 & 5,71 \\
\hline 4 & 35 & 33 & 2 & 5,71 \\
\hline 5 & 35 & 33 & 2 & 5,71 \\
\hline 6 & 35 & 33 & 2 & 5,71 \\
\hline \multicolumn{3}{|c|}{ Average } & 2 & 5,71 \\
\hline
\end{tabular}

The error of the temperature measurement results in our study was smaller than the previous research by Romi in the range: $5.00 \%-5.71 \%$.

So, The results of patient temperature telemetry with IoT technology performs that the temperature with measured data are close to the data of actual temperature measurement by a digital thermometer gun and outperform previous research [12].

\section{CONCLUSION}

The conclusions are that a built device for patient temperature telemetry by applying IoT technology and a wi-fi network that connects a medical or paramedic smartphone has been a good function, that was proven a performance indicator of the error and \%error rate is 0.09 , and $0.248 \%$, respectively.

\section{ACKNOWLEDGMENTS}

This research work was supported by Research Grant 2020 No: 3232/PL6.2.1/LT/2020. The authors would also like to acknowledge the contributions and financial support from the State Polytechnic of Sriwijaya.

\section{REFERENCES}

[1] Aneesh M. Koya*, P.P. Deepthi, Plug and play self-configurable IoT gateway node for telemonitoring of ECG, Computers in Biology and Medicine 112 (2019) 103359.
[2] L. Catarinucci, D.D. Donno, L. Mainetti, L. Palano, L. Patrono, M.L. Stefanizzi, L.Tarricone, An IoT-aware architecture for smart healthcare systems, IEEEInternet Things J. 2 (6) 2015, pp. 515-526,

http://dx.doi.org/10.1109/jiot.2015.2417684

[3] C. Venkatesana, P. Karthigaikumarb, S. Satheeskumaranca, Mobile cloud computing for ECG telemonitoring and real-time coronary heart disease risk detection, Biomedical Signal Processing and Control 44, 2018, pp. 138-145.

[4] Janusz Jezewski, Adam Pawlak, Krzysztof Horoba, Janusz Wrobel, Robert Czabanski, Michal Jezewski, Selected design issues of the medical cyber-physical system for telemonitoring pregnancy at home, 2016.

[5] Olivier Debauchea, Sa“1d Mahmoudia, Pierre Mannebacka, Abdessamad Assila, Fog IoT for Health: A new Architecture for Patients and Elderly Monitoring. Procedia Computer Science 160, 2019, pp. 289-297

[6] Supani Ahyar, Design of flood early warning system with wi-fi network based on a smartphone, AIP Conference Proceedings 1903, 2017, pp. 110001. https://doi.org/10.1063/1.5011627

[7] M. Penhaker, M.Cerny, L. Martinak, J. SpiSak, Biotelemetry System Of Humans, Copyright $(C$ IFAC Programmable Devices and Embedded Systems Bmo, Czech Republic, 2006.

[8] Zafer Al-Makhadmeh, Amr Tolba, 2019, Utilizing IoT wearable medical device for heart disease prediction using higher-order Boltzmann model: A classification approach, Measurement 147, 2019, pp. 106815.

[9] A. Supani, Y.Andriani, A. Taqwa, Ciksadan, Study on implementation of flood early warning system with the internet of things in peri-urban settlement of Palembang for sustainability, IOP Conf. Series: Earth and Environmental Science 202, 2018, pp. 012001

[10] Sandro Nizetic, Petar Solic, Diego Lopez-de-Ipina Gonzalez-de-Artaza, Luigi Patrono, 2020, Internet of Things (IoT): Opportunities, issues, and challenges towards a smart and sustainable future, Journal of Cleaner Production 274, 2020, pp. 122877

[11] Saif Allah H. Almetwally, Mohammed K. Hassan, Mohammed H. Mourad, 2020, Real-Time Internet of Things (IoT) Based Water Quality Management system, Procedia CIRP 91, 2020, pp. 478-485 
[12] Romi Andi Wijaya, Sri Wiji Lestari, Mardiono, Rancang Bangun Alat Monitoring Suhu dan Kelembaban Pada Alat Baby Incubator Berbasis
Internet Of Things, Jurnal Teknologi vol.6, edisi 1, 2018, pp. 52-70. 